\title{
Triglyceride-mimetic structure-gated prodrug nanoparticles for smart cancer therapy
}

Chutong Tianª Jingjing Guo ${ }^{\mathrm{a}}$, Yifan Miao ${ }^{\mathrm{a}}$, Shunzhe Zheng ${ }^{\mathrm{a}}$, Bingjun Sun ${ }^{\mathrm{a}}$, Mengchi Sun ${ }^{\mathrm{a}}$, Qing Ye $^{\mathrm{a}}$, Wenxue Liu ${ }^{\mathrm{b}}$, Shuang Zhou ${ }^{\mathrm{a}}$, Ken-ichiro Kamei ${ }^{\mathrm{a}, \mathrm{c}, *}$, Zhonggui He ${ }^{\mathrm{a}, *}$ and Jin Sun ${ }^{\mathrm{a}, *}$

a Department of Pharmaceutics, Wuya College of Innovation, Shenyang Pharmaceutical University, Shenyang, Liaoning 110016, PR China

b Department of Pharmaceutics, School of Pharmacy, Shenyang Pharmaceutical University, Shenyang, Liaoning 110016, PR China

${ }^{\mathrm{c}}$ Institute for Integrated Cell-Material Sciences, Kyoto University, Kyoto, 606-8501, Japan

*Corresponding authors:

Prof. Ken-ichiro Kamei

Department of Pharmaceutics, Wuya College of Innovation, Shenyang Pharmaceutical University, Shenyang 110016, P. R. China

E-mail: Kamei.kenichiro.7r@kyoto-u.ac.jp

Prof. Zhonggui He

Department of Pharmaceutics, Wuya College of Innovation, Shenyang Pharmaceutical University, Shenyang 110016, P. R. China

E-mail: hezhonggui@vip.163.com

Prof. Jin Sun

Department of Pharmaceutics, Wuya College of Innovation, Shenyang Pharmaceutical University, Shenyang 110016, P. R. China

E-mail: sunjin@syphu.edu.cn 


\section{Table of Contents}

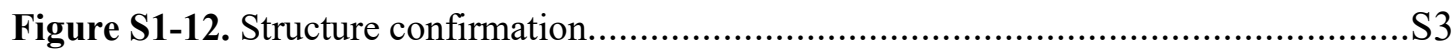

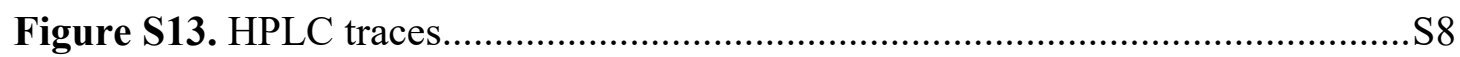

Figure S14. TEM images of the non-PEGylated prodrug NPs............................ S9

Figure S15. DSSTG (4) structure and its dimerization free energy changes ............ S9

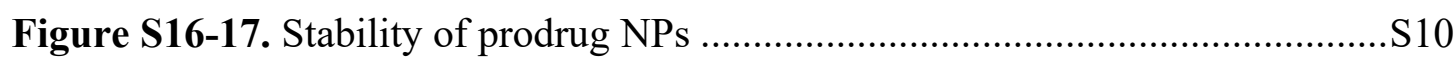

Figure S18. HPLC trances of DSSTG (2) NPs with different release mediums.......S10

Figure S19. Mass spectra of intermediates in in vitro release study........................ S11

Figure S20. In vitro degradation of the prodrugs in different medium ...................S12

Figure S21. Cumulative release of DTX from DSSTG (2) NPs or DSSTG (2) prodrug

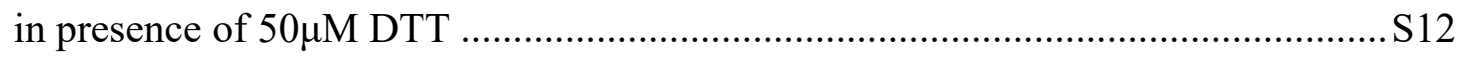

Figure S22. TEM images of prodrug NPs in the presence of DTT and lipase .........S12

Figure S23. Viability of cells after treatment for $72 \mathrm{~h} \mathrm{.........................................S13}$

Figure S24. Intracellular GSH concentrations of different cells............................S13

Figure S25. Quantitative analysis of ex vivo distribution .......................................S13

Figure S26. Hepatic and renal function indicators of mice after treatment and H\&E staining of the major organs and tumors after treatments ..................................... S14

Table S1. Characterization of DSSTG NPs without DSPE-PEG 2 K.........................S14

Table S2. Characterization of prodrug nanoparticles incubated with DTT and lipase

Table S3. Characterization of PSSTG NPs.

Table S4. Cytotoxicity (IC 50 values) of DTX and prodrug NPs to tumor cell lines and normal cells

Table S5. The selectivity index (SI) of prodrug NPs between normal cells and tumor cells after being incubated for $72 \mathrm{~h}$..... S16

Table S6. Pharmacokinetic parameters of DTX and prodrug NPs S16 


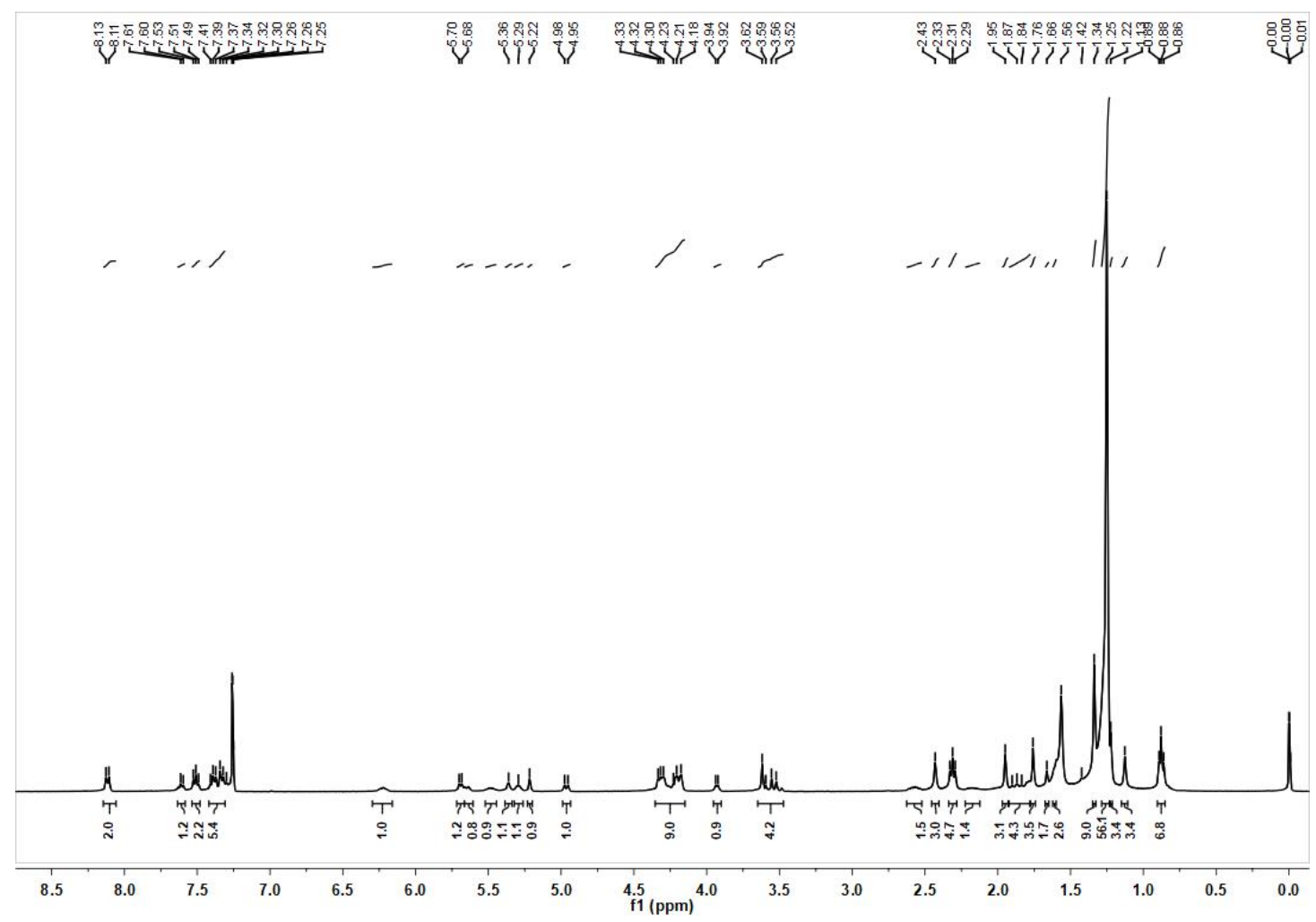

Figure S1. ${ }^{1} \mathrm{HNMR}$ spectra of DSSTG (0).

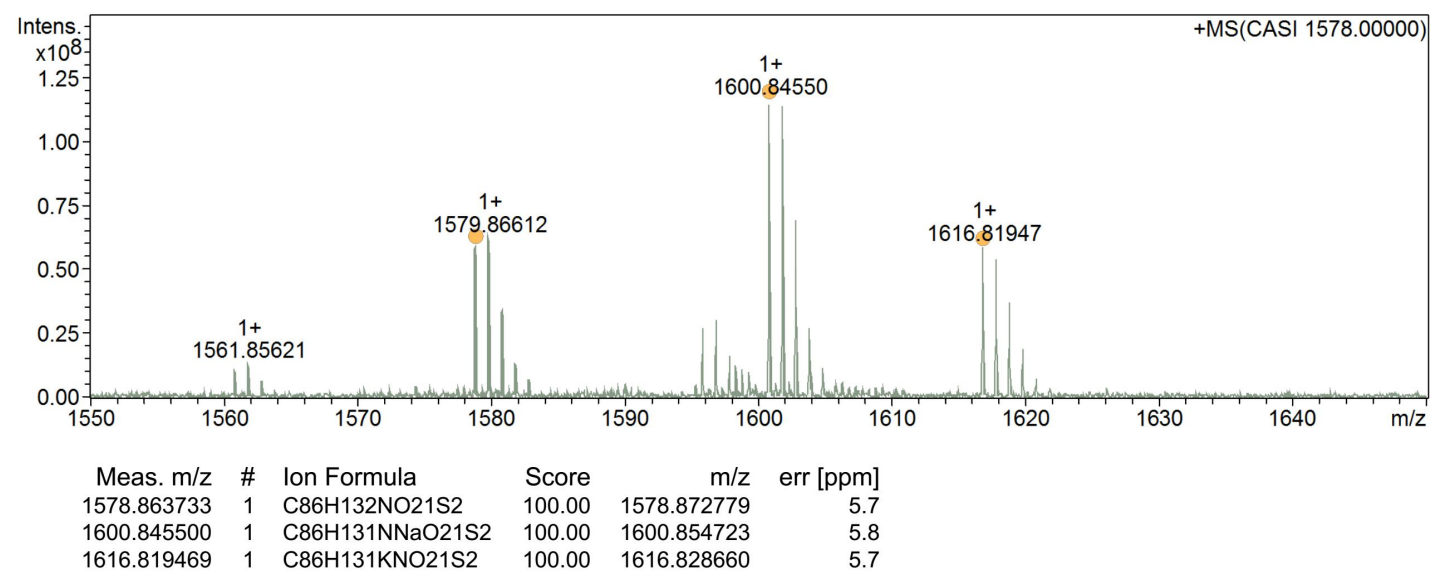

Figure S2. Mass spectra of DSSTG (0). 


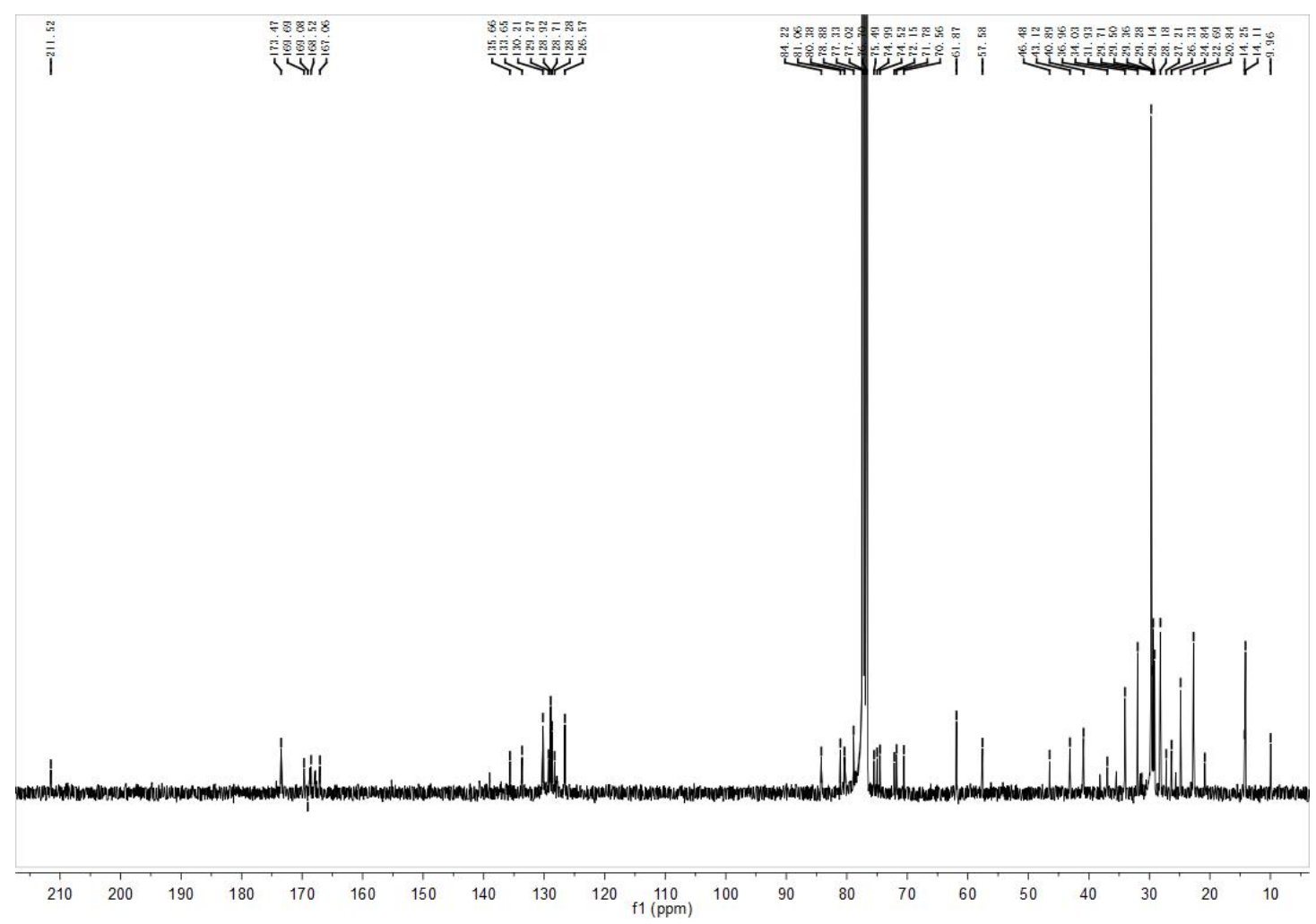

Figure S3. ${ }^{13} \mathrm{C}$ NMR spectra of DSSTG (0).

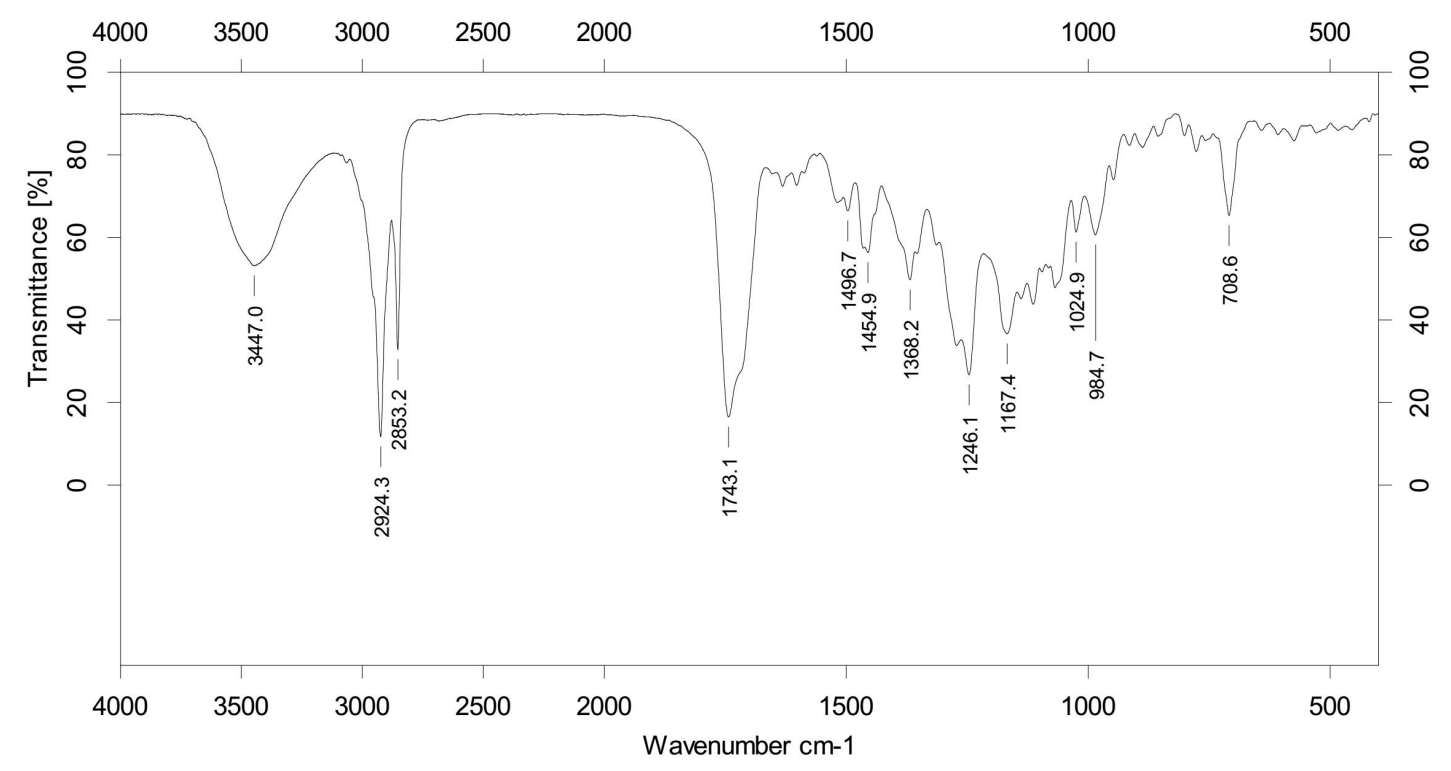

Figure S4. Infrared spectra of DSSTG (0). 


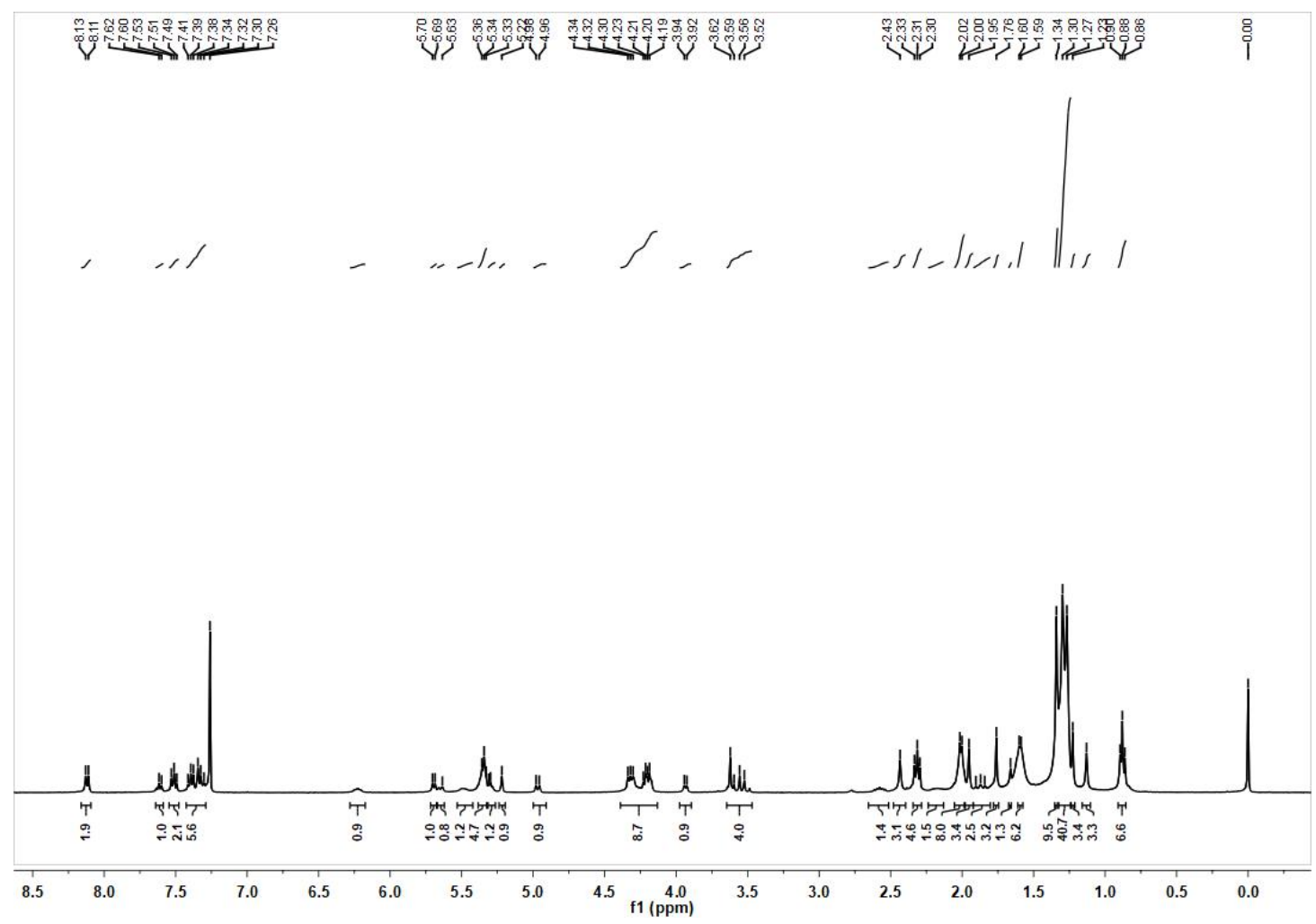

Figure S5. ${ }^{1} \mathrm{H}-\mathrm{NMR}$ spectra of DSSTG (1).

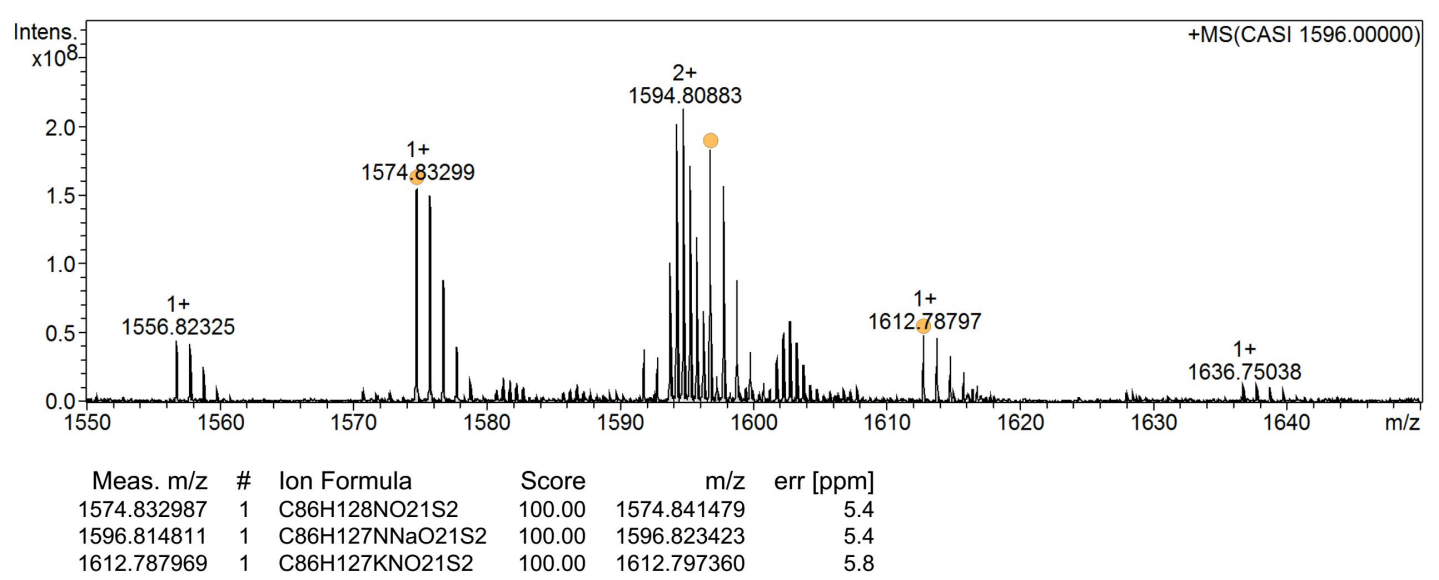

Figure S6. Mass spectra of DSSTG (1). 


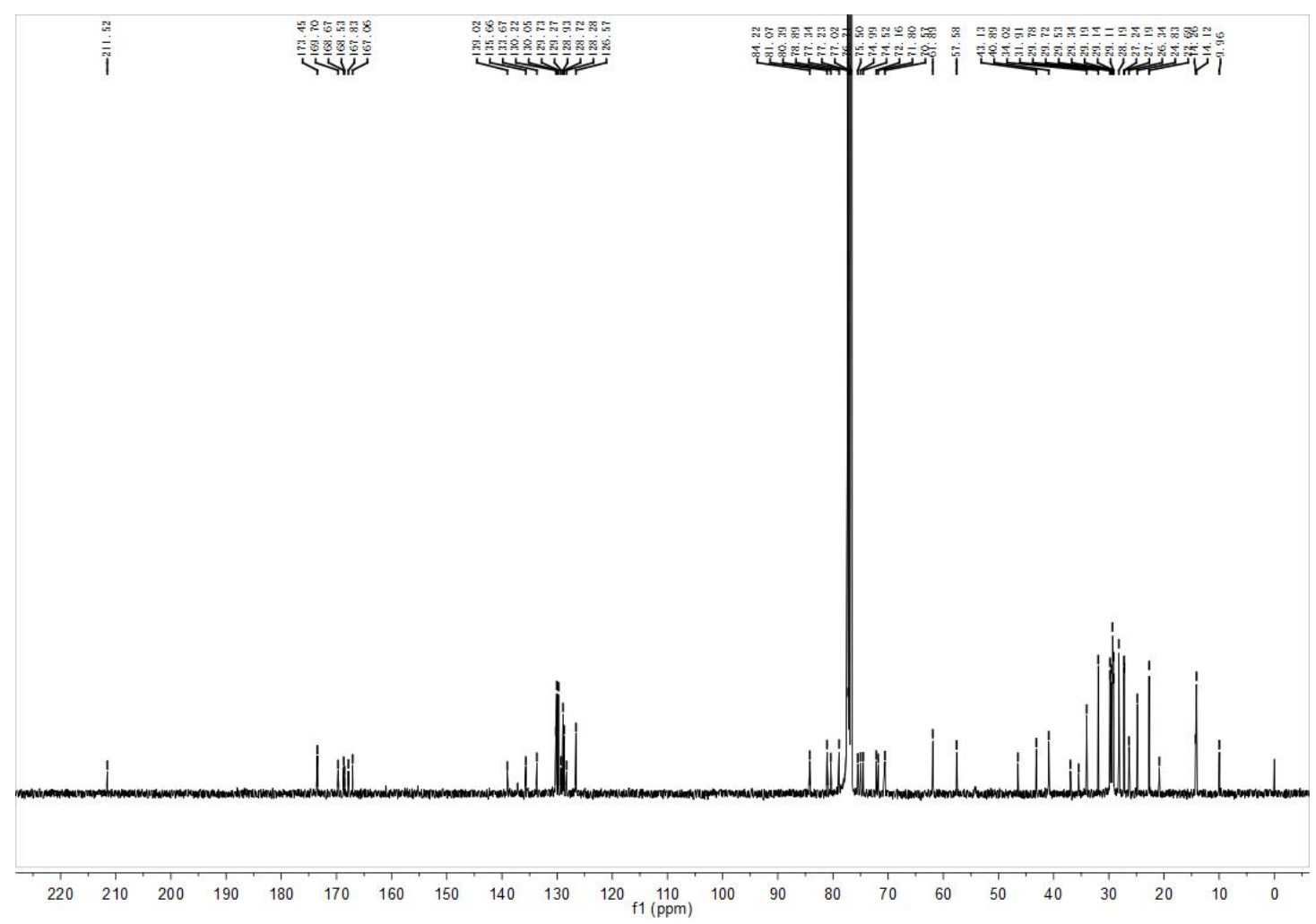

Figure S7. ${ }^{13} \mathrm{C}$ NMR spectra of DSSTG (1).

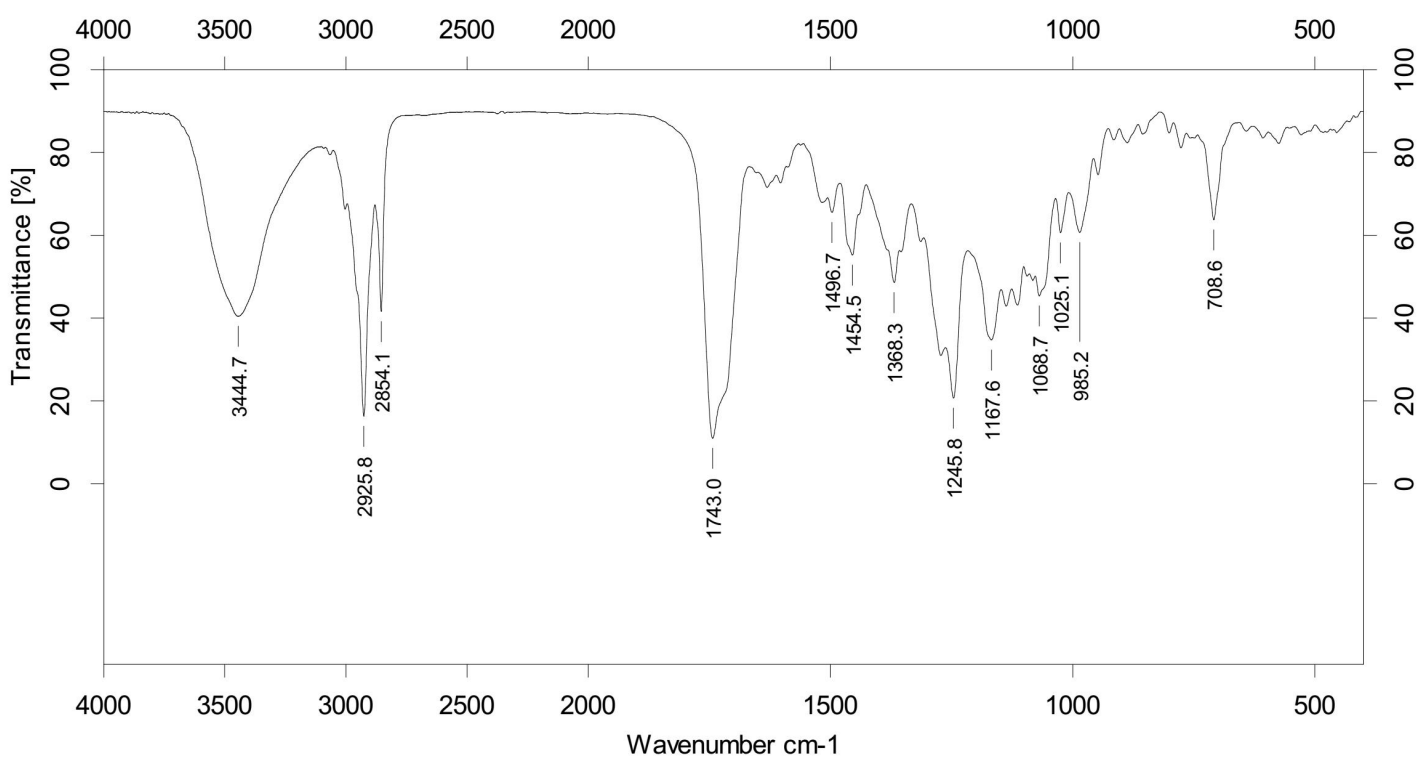

Figure S8. Infrared spectra of DSSTG (1). 


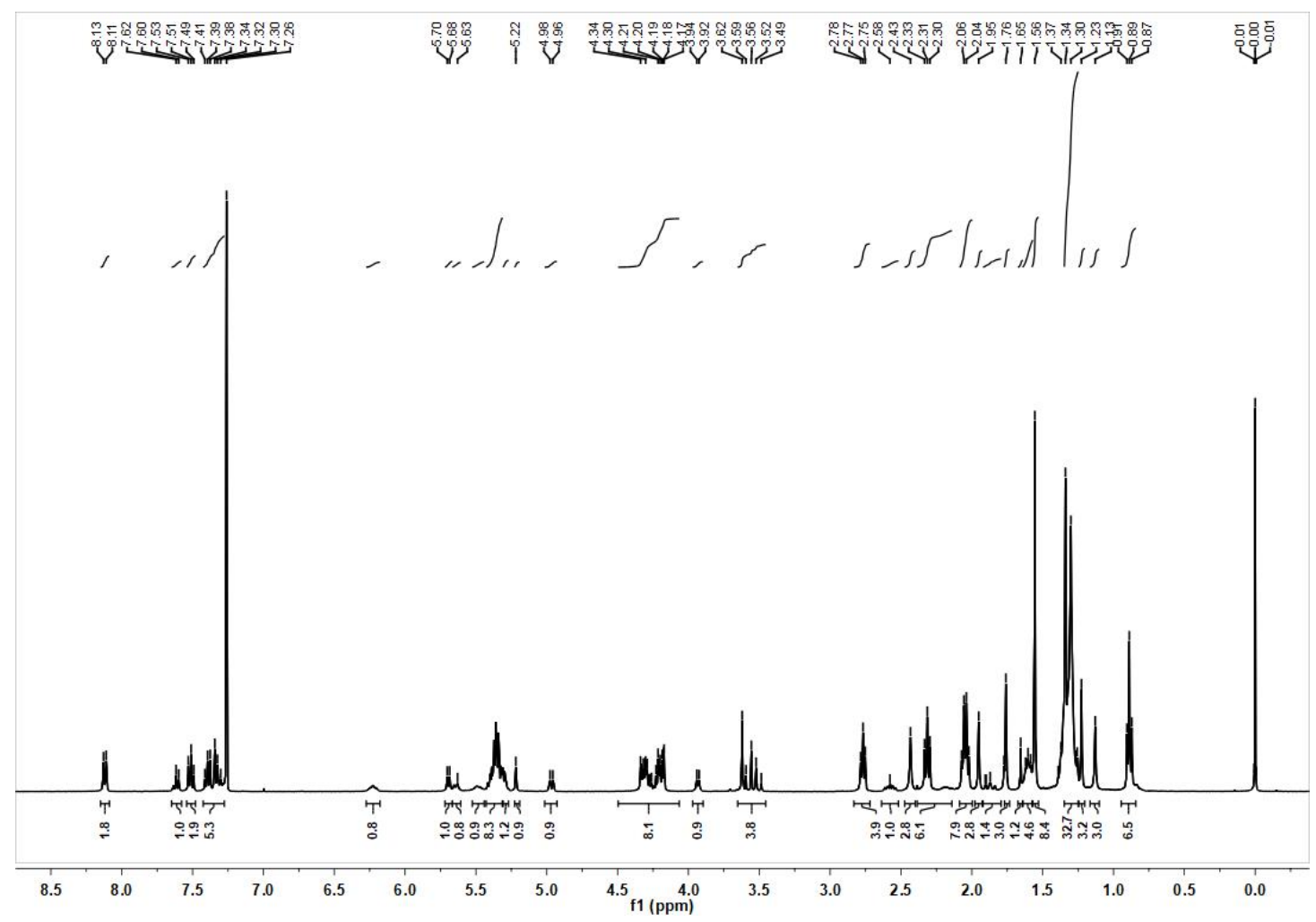

Figure S9. ${ }^{1} \mathrm{H}-\mathrm{NMR}$ spectra of DSSTG (2).

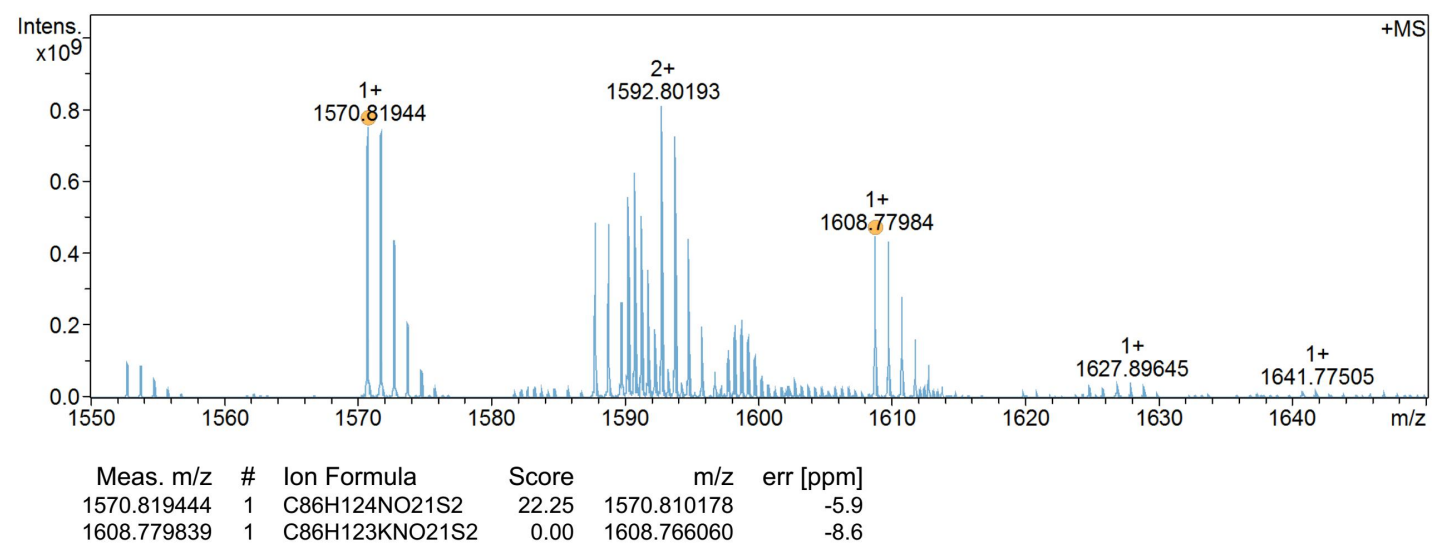

Figure S10. Mass spectra of DSSTG (2). 

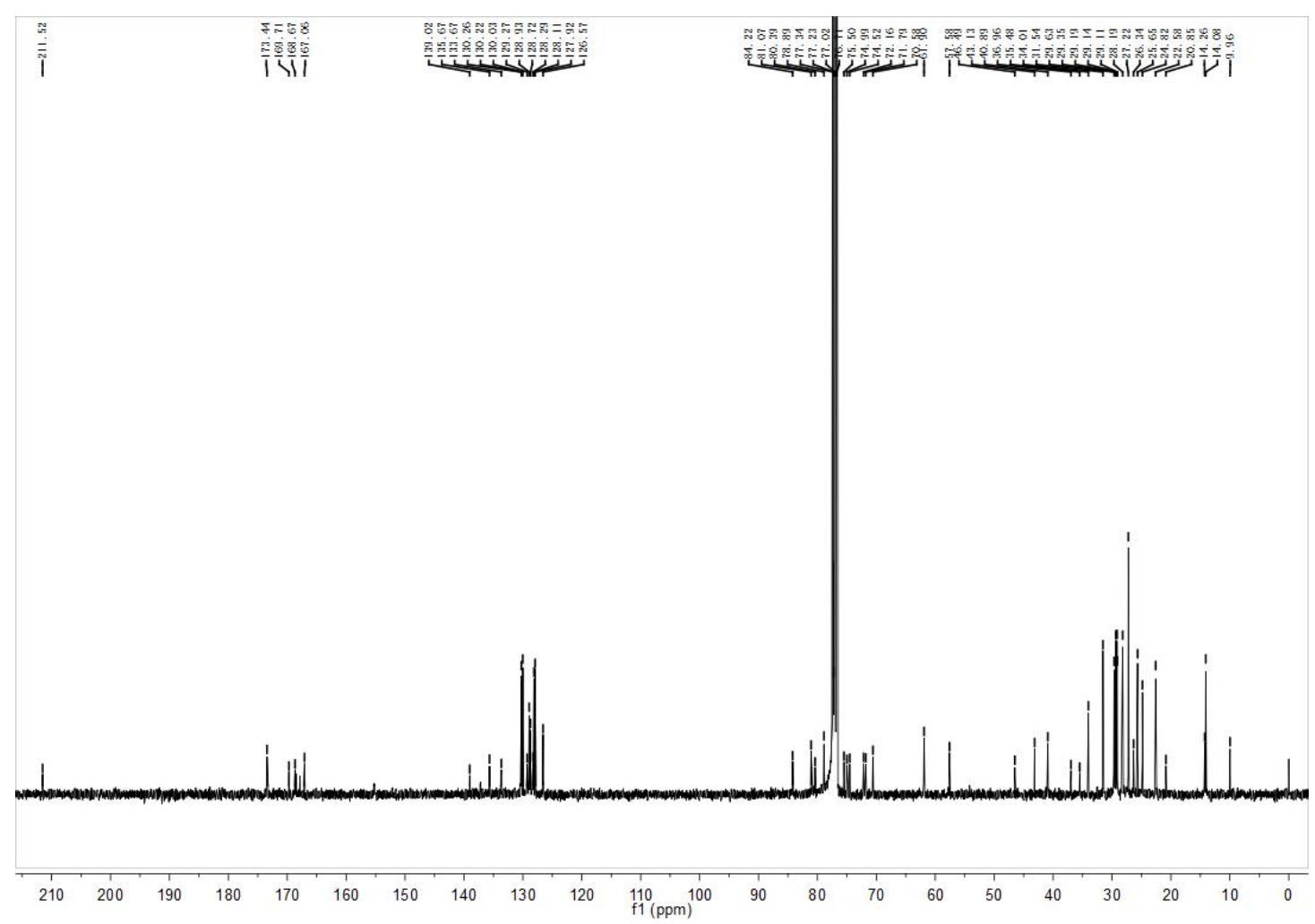

Figure S11. ${ }^{13} \mathrm{C}$ NMR spectra of DSSTG (2).

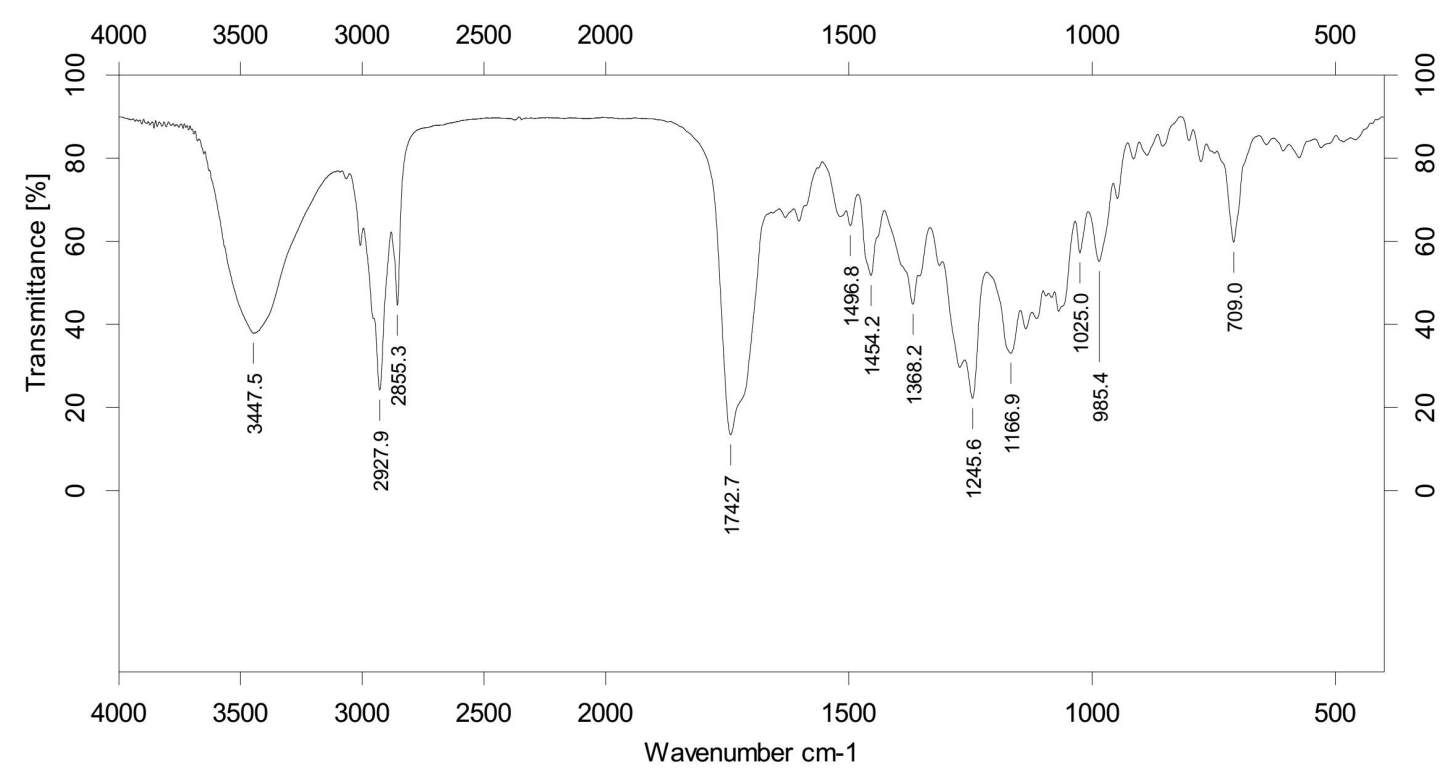

Figure S12. Infrared spectra of DSSTG (2).

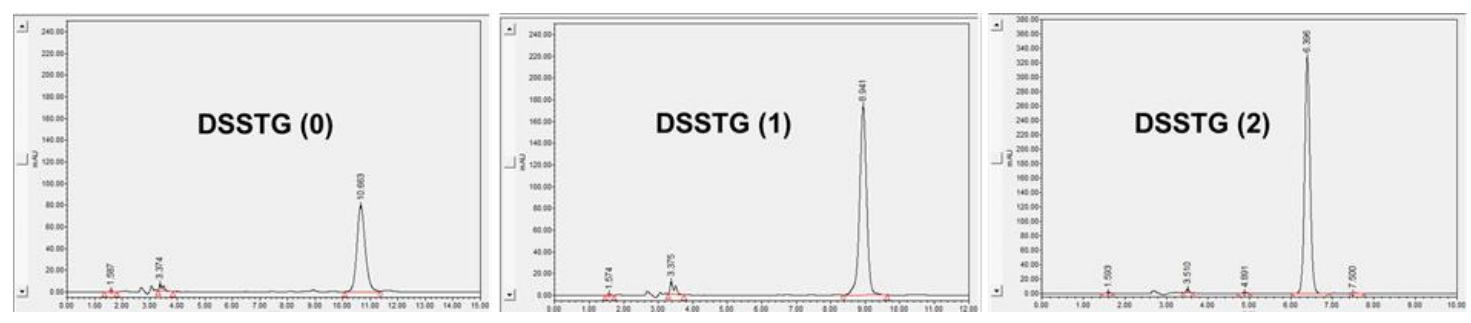

Figure S13. HPLC traces of the prodrugs. 


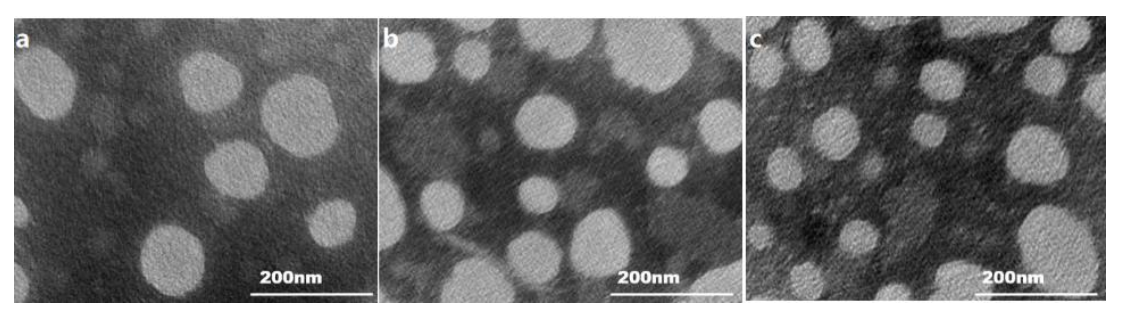

Figure S14. TEM images of the non-PEGylated prodrug NPs. (a) DSSTG (0); (b) DSSTG (1); (c) DSSTG (2).

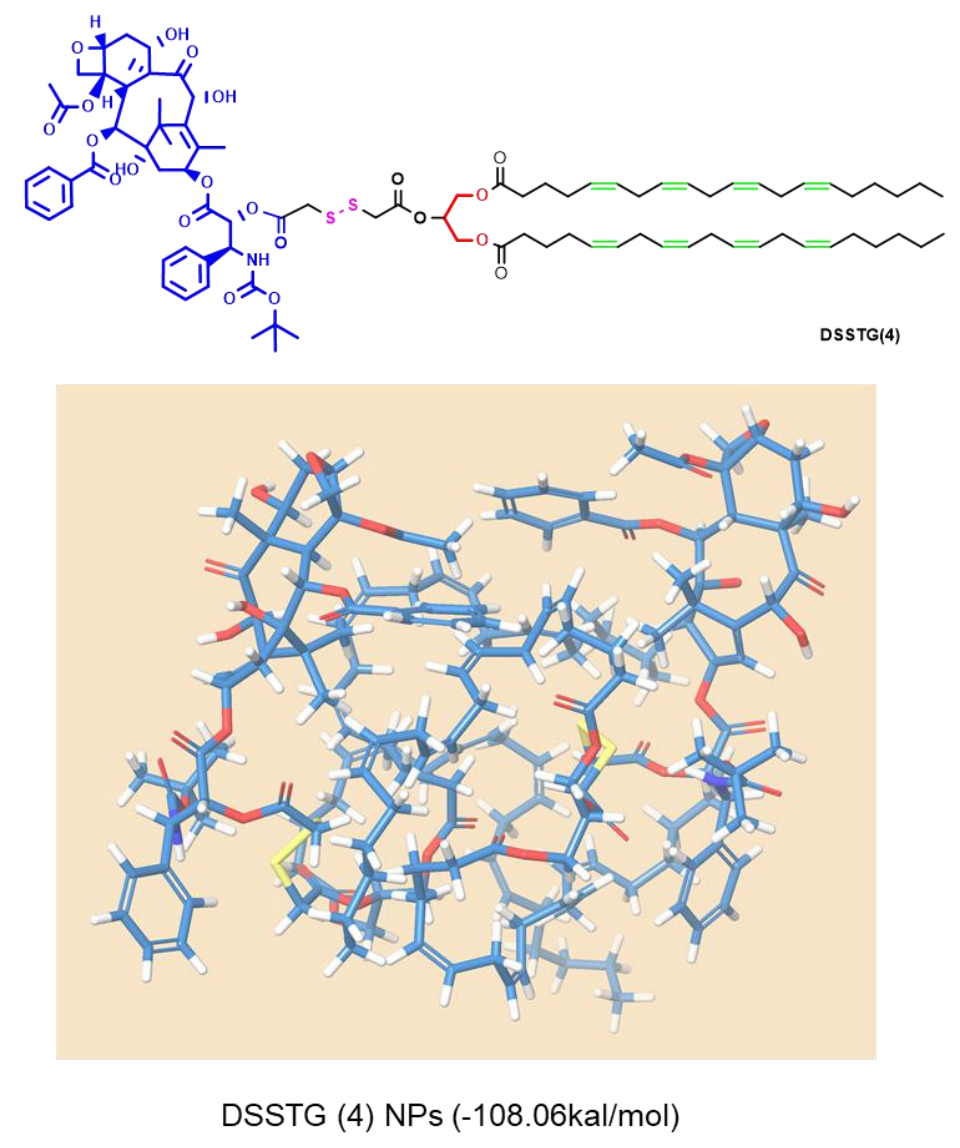

Figure S15. Structure of the DSSTG (4) and its free energy changes during the dimerization. 


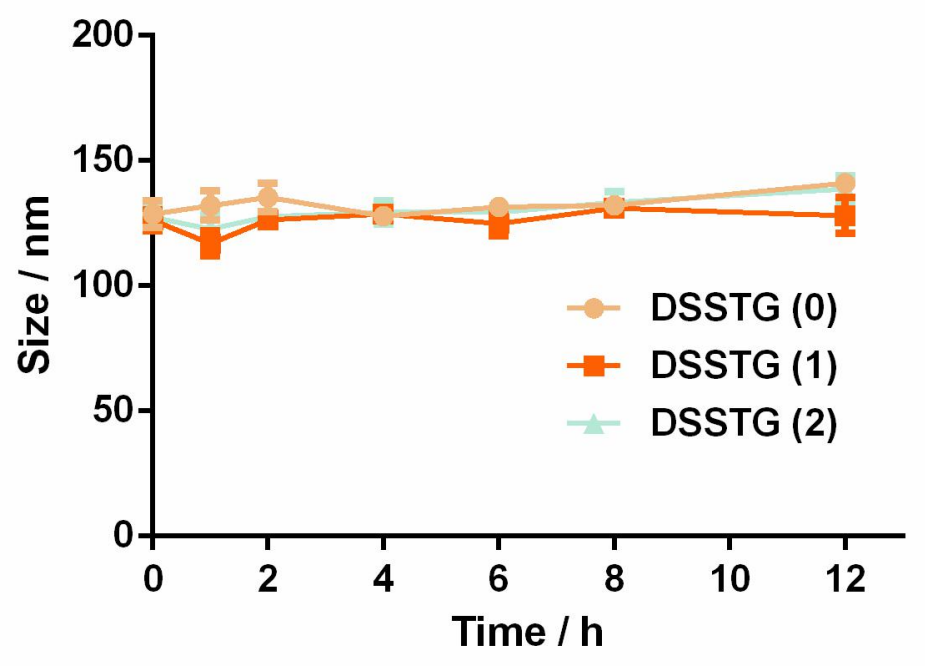

Figure S16. Stability of prodrug NPs analyzed by DLS after incubation in PBS (pH 7.4) supplemented with $10 \%$ FBS at $37{ }^{\circ} \mathrm{C}$.

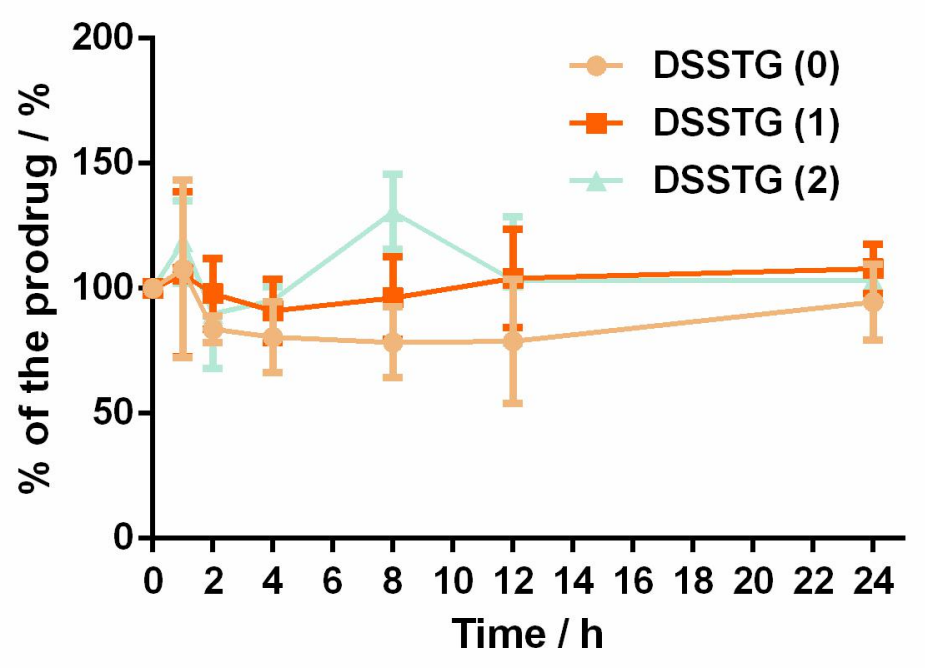

Figure S17. Stability of prodrug NPs analyzed by HPLC after incubation in PBS (pH 7.4) supplemented with $10 \%$ FBS at $37{ }^{\circ} \mathrm{C}$.

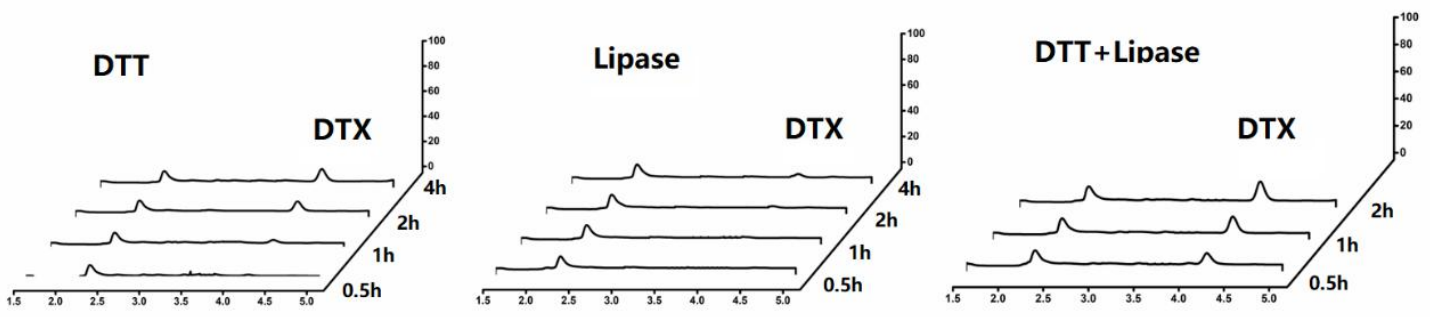

Figure S18. HPLC chromatograms of DSSTG (2) prodrug NPs with different release 
mediums.
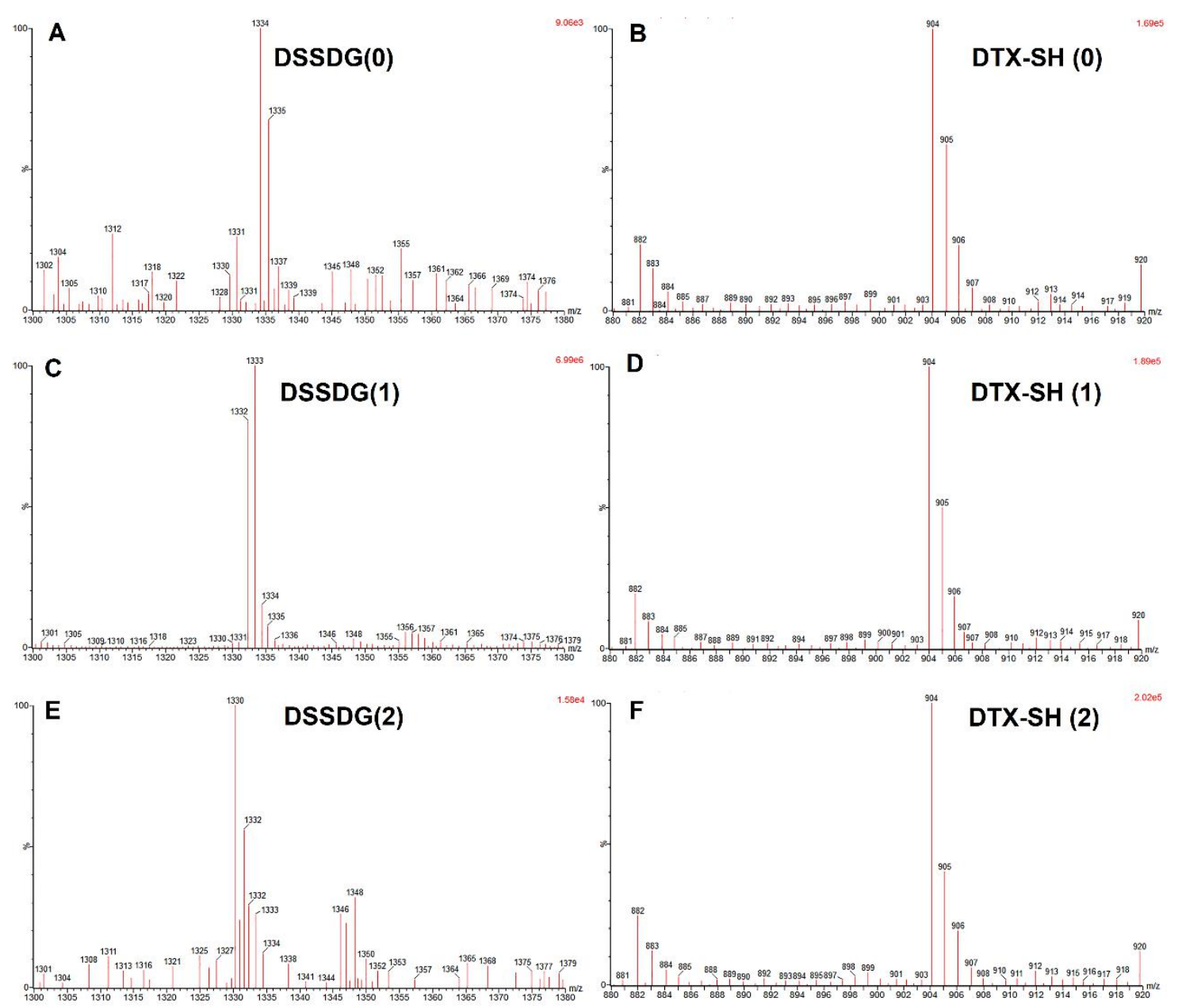

Figure S19. Mass spectra of (A)DSSDG (0), (C) DSSDG (1), (E) DSSDG (2) from the prodrug NPs incubated with lipase and DTT-containing release media after $0.5 \mathrm{~h}$, respectively. Mass spectra of DTX-SH from the (B)DSSTG (0), (D) DSSTG (1), (F) DSSTG (2) NPs incubated with lipase and DTT-containing release media after $0.5 \mathrm{~h}$, respectively. 

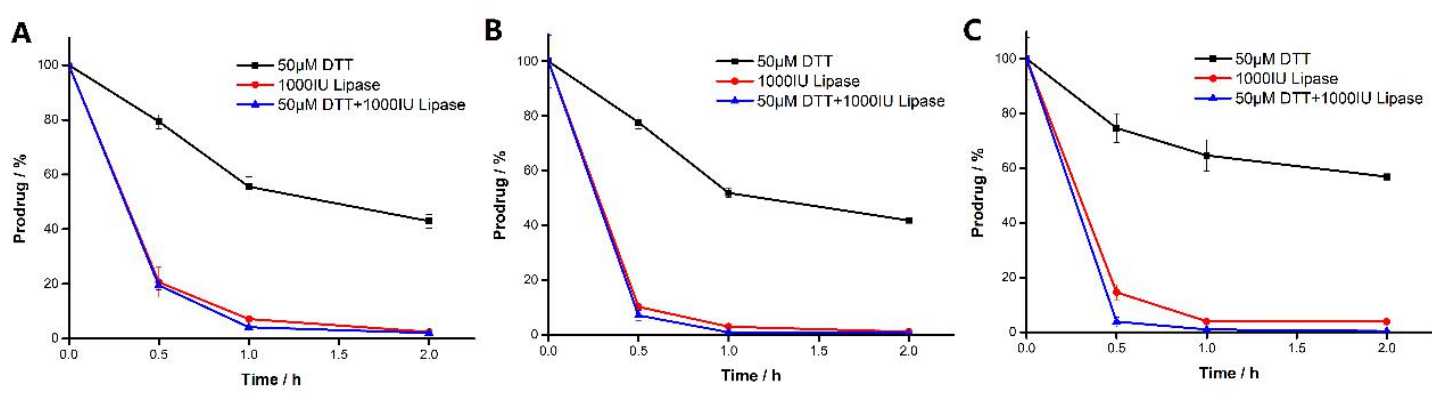

Figure S20. In vitro degradation of the prodrugs in different medium. (A) DSSTG (0);

(B) DSSTG (1); (C) DSSTG (2).

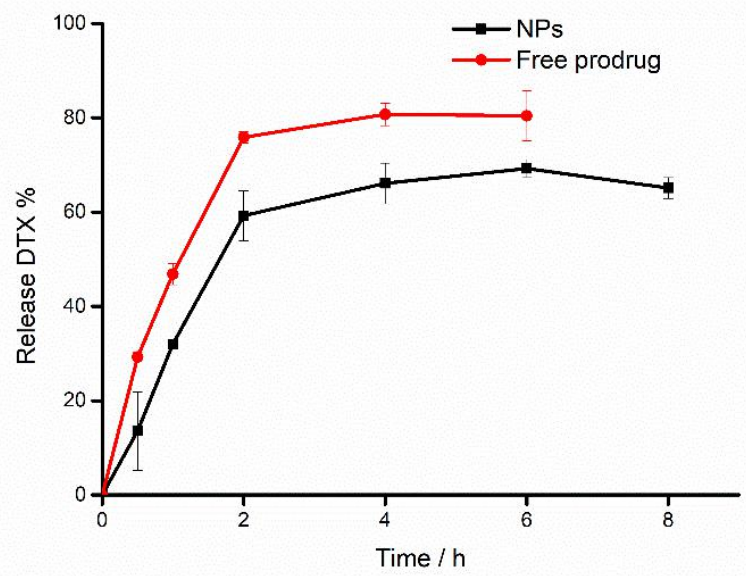

Figure S21. Cumulative release of DTX from DSSTG (2) NPs or DSSTG (2) prodrug in presence of $50 \mu \mathrm{M}$ DTT.

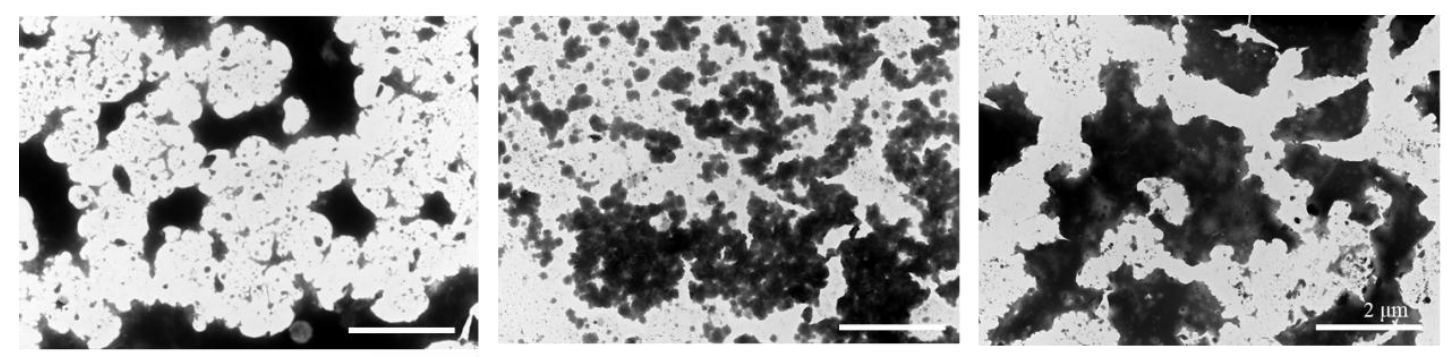

Figure S22. TEM images of prodrug NPs (DSSTG (0), DSSTG (1) and DSSTG (2) from left to right) in the presence of DTT and lipase for $2 \mathrm{~h}$. 

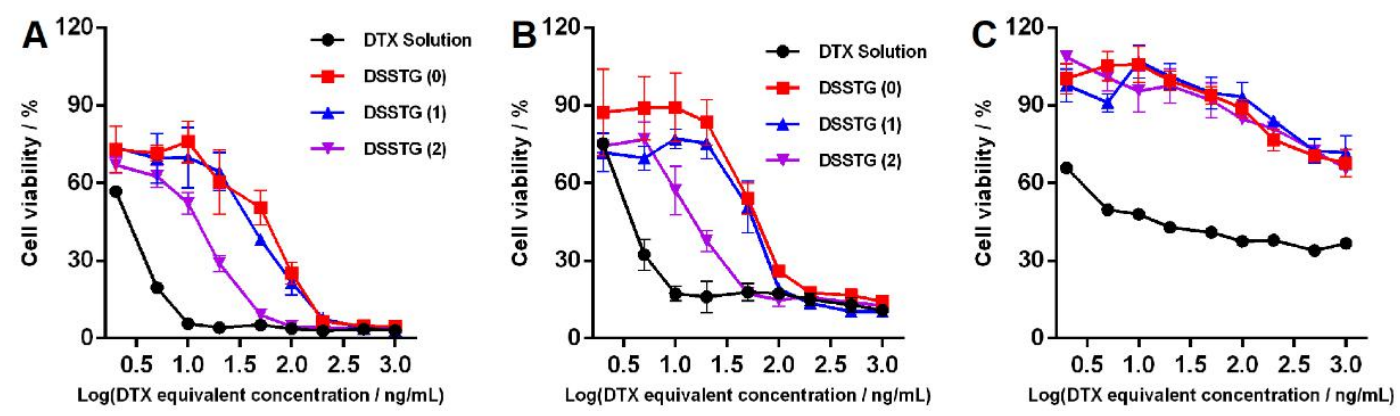

Figure S23. Viability of (A) RM-1, (B) 4T1 and (C) L02 cells after treated with various concentrations of DTX solution and prodrug NPs for $72 \mathrm{~h}$, respectively.

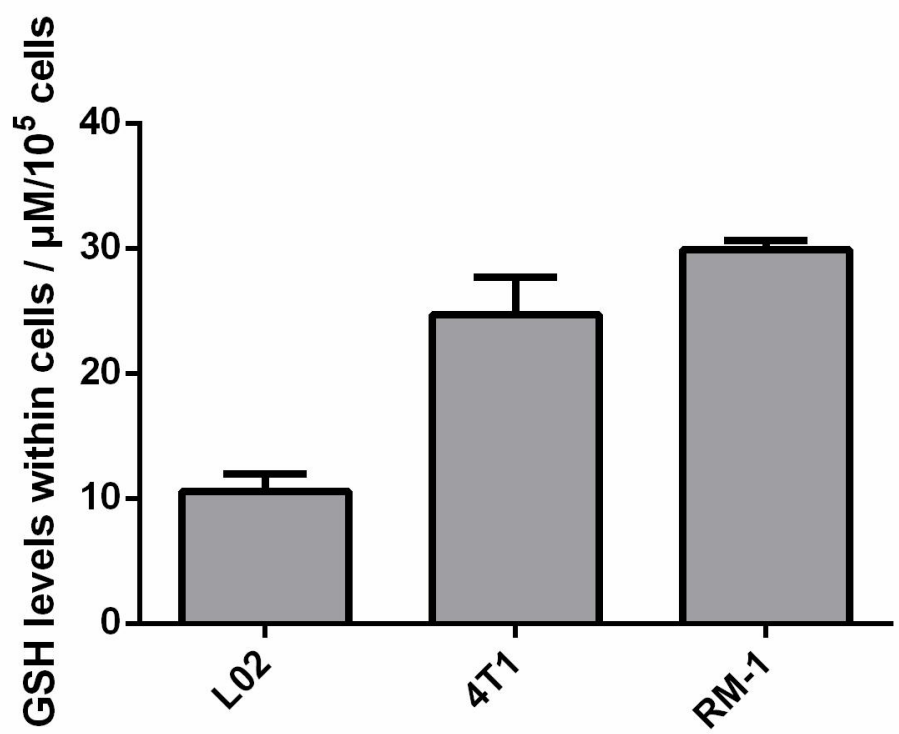

Figure S24. Intracellular GSH concentrations of the L02, 4T1 and RM-1 cells. All data are presented as mean $\pm \operatorname{SD}(n=3)$.
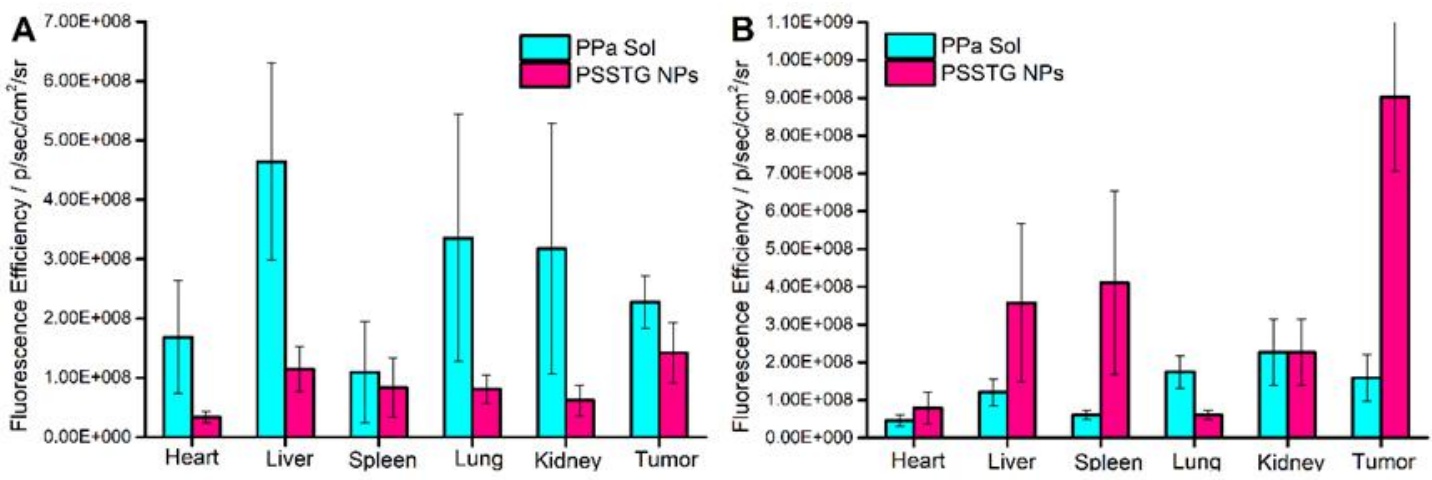

Figure S25. Quantitative analysis of ex vivo distribution of the PSSTG NPs and PPa solution at (A)1 h; (B)12h. 

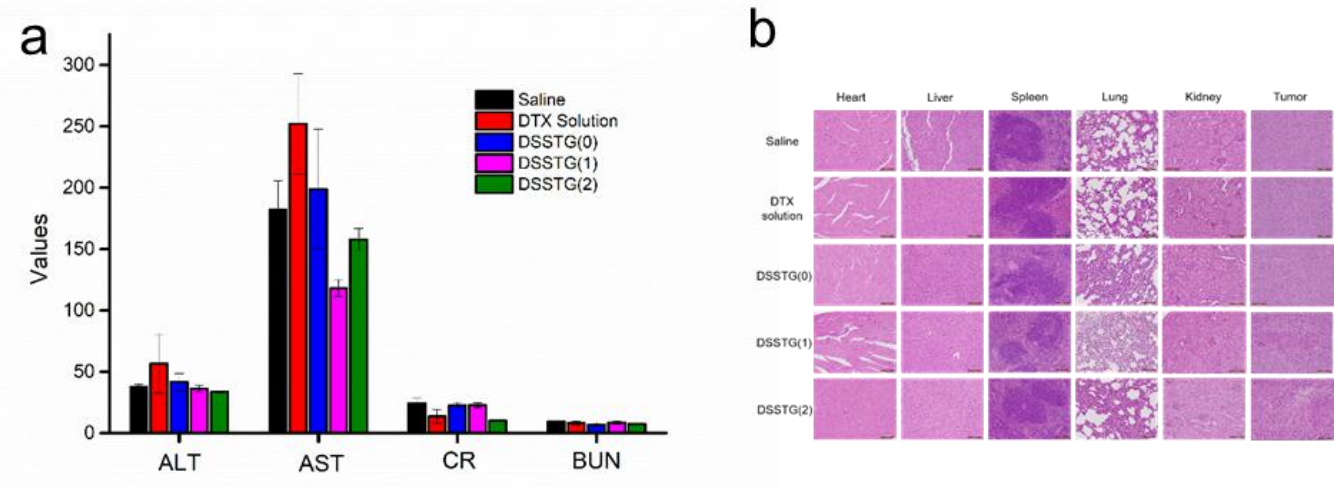

Figure S26. (a) Hepatic and renal function indicators of mice after treatment (data are presented as mean $\pm \mathrm{SD}, \mathrm{n}=3$ ). (b) $\mathrm{H} \& \mathrm{E}$ staining of the major organs and tumors after treatments.

Table S1. Characterization of DSSTG NPs without DSPE-PEG $2 \mathrm{~K}(\mathrm{n}=3)$.

\begin{tabular}{ccc}
\hline Formulations & Size (nm) & Size (nm) $^{\mathbf{a}}$ \\
\hline DSSTG (0) NPs & $123 \pm 2.06$ & $199 \pm 6.58$ \\
DSSTG (1) NPs & $122 \pm 5.16$ & $194 \pm 3.69$ \\
DSSTG (2) NPs & $114 \pm 4.46$ & $145 \pm 4.80$ \\
\hline
\end{tabular}

a: the size of prodrug NPs after diluted with pH 7.4 PBS (containing 10\% FBS). 
Table S2. Characterization of prodrug nanoparticles incubated with DTT and lipase for $2 \mathrm{~h}(\mathrm{n}=3)$.

\begin{tabular}{ccc}
\hline Formulations & Size (nm) & PDI \\
\hline DSSTG (0) NPs & $1117 \pm 50$ & $0.39 \pm 0.13$ \\
DSSTG (1) NPs & $1353 \pm 55$ & $0.55 \pm 0.43$ \\
DSSTG (2) NPs & $1404 \pm 275$ & $0.29 \pm 0.04$ \\
\hline
\end{tabular}

Table S3. Characterization of PSSTG NPs (data are represented as mean $\pm \mathrm{SD}, \mathrm{n}=3$ ).

\begin{tabular}{cccc}
\hline Formulations & Size $(\mathrm{nm})$ & PDI & $\begin{array}{c}\text { Zeta Potential } \\
(\mathrm{mV})\end{array}$ \\
\hline PSSTG & $129.4 \pm 4.46$ & $0.14 \pm 0.04$ & $-14.8 \pm 3.50$ \\
\hline
\end{tabular}

Table S4. Cytotoxicity ( $\mathrm{IC}_{50}$ values) of DTX and prodrug NPs to two tumor cell lines and normal cells.

\begin{tabular}{ccccccc}
\hline \multirow{2}{*}{ Formulations } & \multicolumn{2}{c}{$\mathrm{RM}-1(\mathrm{ng} / \mathrm{mL})$} & \multicolumn{2}{c}{$4 \mathrm{~T} 1(\mathrm{ng} / \mathrm{mL})$} & \multicolumn{2}{c}{ L02 $(\mathrm{ng} / \mathrm{mL})$} \\
\cline { 2 - 7 } & $48 \mathrm{~h}$ & $72 \mathrm{~h}$ & $48 \mathrm{~h}$ & $72 \mathrm{~h}$ & $48 \mathrm{~h}$ & $72 \mathrm{~h}$ \\
\hline DTX & 2.8 & 2.1 & 12.4 & 3.2 & 215.0 & 10.2 \\
DSSTG (0) & 76.4 & 27.5 & 237.6 & 56.5 & - & 2687.0 \\
DSSTG (1) & 20.7 & 22.6 & 156.1 & 33.4 & - & 2624.0 \\
DSSTG (2) & 10.0 & 7.5 & 84.7 & 12.7 & - & 2880.0 \\
\hline
\end{tabular}


Table S5. The selectivity index (SI) of prodrug NPs between normal cells and tumor cells after being incubated for $72 \mathrm{~h}$. SI=(IC 50 normal $) /\left(\mathrm{IC}_{50 \text { tumor }}\right)$. ("IC 50 normal and $\mathrm{IC}_{50 \text { tumor" }}$ is the $\mathrm{IC}_{50}$ of prodrug NPs toward normal cells and tumor cells, respectively).

\begin{tabular}{ccccc}
\hline Cell lines & Taxol & DSSTG (0) NPs & DSSTG (1) NPs & DSSTG (2) NPs \\
\hline RM-1-72h & 4.86 & 97.71 & 116.11 & 384.00 \\
$4 \mathrm{~T} 1-72 \mathrm{~h}$ & 3.19 & 47.56 & 78.56 & 226.77 \\
\hline
\end{tabular}

Table S6. Pharmacokinetic parameters of DTX and prodrug NPs (n=5).

\begin{tabular}{ccccc}
\hline \multirow{2}{*}{ Formulations } & \multicolumn{3}{c}{ DTX } \\
\cline { 2 - 5 } & $\begin{array}{c}\text { AUC }(0-24) \\
(\mathrm{nmol} / \mathrm{ml} * \mathrm{~h})\end{array}$ & $\mathrm{t}_{1 / 2}(\mathrm{~h})$ & $\begin{array}{c}\text { AUC }(0-24) \\
\left.(\mathrm{nmol} / \mathrm{ml})^{\mathrm{h}}\right)\end{array}$ & $\mathrm{t}_{1 / 2}(\mathrm{~h})$ \\
\hline DTX & - & - & $2.68 \pm 2.55$ & $0.21 \pm 0.01$ \\
DSSTG (0) & $16.31 \pm 2.64$ & $0.27 \pm 0.04$ & $9.29 \pm 2.31$ & $0.58 \pm 0.47$ \\
DSSTG (1) & $14.57 \pm 9.16$ & $0.62 \pm 0.62$ & $8.21 \pm 1.50$ & $0.24 \pm 0.02$ \\
$\operatorname{DSSTG}(2)$ & $31.27 \pm 7.76$ & $0.37 \pm 0.41$ & $4.63 \pm 1.09$ & $0.42 \pm 0.12$ \\
\hline
\end{tabular}

